\title{
Economy and fashion: analysing the use of simulated leather upholstery in a nineteenth century Australian coach
}

Natalie Ison ${ }^{1 *}$, Alison Wain ${ }^{2}$ and Jurian Hoogewerff ${ }^{2}$

\begin{abstract}
The Ranken coach is a landau style horse-drawn vehicle brought to the Australian colony of New South Wales in the 1820s, and now held in the National Historical Collection of the National Museum of Australia. At some point, or points, in the vehicle's history the roof structure has been altered and parts of its original interior and exterior upholstery have been replaced with black coated fabrics resembling imitation leather. Three data sources were brought together to support the hypothesis that the alterations to the coach were made between 1923 and 1938. Two of these sources were historical research on the vehicle and research on materials used to simulate leather in the times when the coach was likely to have been altered. These were used to determine the likely dates for these changes, as well as the types of materials available at the time. The third source involved physical means of investigation to study the chemical composition of the coatings. These included visual inspection, Ultraviolet fluorescence evaluation, solubility tests, the diphenylamine spot test, Fourier transform infrared spectroscopy, and pyrolysis gas chromatography, mass spectroscopy. The hypothesis formed was that the fabric used for the new interior upholstery was probably coated with an alkyd-based formulation, and that the fabric used for the new roof coating was probably coated with a cellulose nitrate based formulation. One of the key findings of this research was that the composition of the alkyd-based material does not exactly mirror modern formulations. This could be due to age-related deterioration, to the lack of standardisation in early formulations, or the fact that at the period in question, it appears to have been common to mix concoctions at the point of application. The physical analyses also supported hints in the historical documentation that topical "varnishes" may have been applied separately over the coated fabrics to improve their appearance and weatherproofing.
\end{abstract}

Keywords: Ranken coach, National Museum of Australia, Conservation, FTIR, Py-GC-MS, Coated fabric, Imitation leather, Upholstery

\section{Background}

The horse-drawn vehicle known as the Ranken coach, held in the National Museum of Australia (NMA), is one of Australia's oldest surviving horse-drawn vehicles. The coach was either imported to, or purchased in, Australia by wealthy immigrant George Ranken in the 1820s, and used by him throughout his life in and around the town of Bathurst until his death in 1860. After this, the coach was acquired for use as a mourning vehicle by the Hodge

\footnotetext{
*Correspondence: Natalie.ison@nma.gov.au

${ }^{1}$ National Museum of Australia, Canberra, Australia

Full list of author information is available at the end of the article
}

family, who ran an undertakers' business in Bathurst. In 1924, the Hodge family donated the coach to the Royal Australian Historical Society (RAHS) where it remained until its acquisition by the NMA in 1980 [1].

The coach was originally a landau, able to seat four to six people in a face-to-face arrangement, and with a roof that opened from the centre to an angle of $45^{\circ}$ [2]. At some point in its history, the coach was modified, which prevented the roof opening, and parts of it were re-upholstered in black-coated fabrics, which appear to be imitation leathers. Conservation assessment and treatment of the vehicle for display raised questions about the dates and sequence of these alterations; the composition 
and use of early coated fabrics in Australia; and the roles that the coach played in the life of the young colony.

The research reported here was undertaken through archival and photographic research into the history of the vehicle, physical analysis of samples of the coated materials found on the coach, and a review of literature on the manufacture, applications and chronology of coated fabrics from the mid nineteenth to mid twentieth centuries. The principle period of interest is from 1820 (which is the earliest known mention of the coach), to 1940, which historical and chemical research indicates is the latest probable date for modification and re-upholstery of the coach to have been undertaken.

\section{Physical evidence of alteration}

Detailed visual inspections of the coach were conducted by conservators at the NMA in 1983 and again in 2012 . These provided evidence of a variety of alterations to the coach's physical construction and upholstery. These alterations included the following:

\section{Roof closure}

The coach roof was altered which prevented it being opened. This was done by placing wood and large metal braces across the roof and covering the inside and outside of the new structure with a woven fabric coated with a black material (hereafter referred to as the "roof coating"). The samples used for analysis of the roof coating came from the top of the vehicle, near the metal brackets.

\section{Interior re-upholstery}

The inside of the Ranken coach was altered by installing padded wall panels. These panels are rigid and run from the seat-backs to the ceiling, providing an impediment to opening the roof. It is possible that they were added to provide support for the permanently closed roof structure. The wall panels match the door panels and cushions and are upholstered in a woven fabric coated with a black material (hereafter collectively referred to as the "interior upholstery"). Buttons are arranged to form square shapes in the padding, a design known as "biscuit". The samples used for analysis of the interior upholstery came from the seat cushions.

\section{Prior alterations}

It should be noted that the alterations visible on the coach today may be merely the last in a sequence of changes made to refurbish worn or shabby components, to bring the coach up to date with changes in fashion, or to alter its function for new uses.

\section{The history of the Ranken coach}

Historical research was undertaken to identify when the current roof configuration and coating, and current interior upholstery, were installed. This showed that while there are references in a number of sources to the coach and its use during the nineteenth and twentieth centuries, there a few explicit mentions of physical work or maintenance on the vehicle. The sources that have been located and examined are detailed below. These sources have been used to create a timeline for the alterations to the coach (Fig. 1).

The first known photo of the coach (Fig. 2) was published in an article in the National Advocate in 1923 [3]. This was just before the Hodge family donated the coach to the RAHS in 1924 and in the photograph, the interior door panel of the coach can be seen, but without the distinctive biscuit pattern upholstery that is present today. A 1938 photograph of the coach (Fig. 3) in the RAHS magazine does show the biscuit pattern upholstery [4], and this means that the biscuit pattern material must have been installed between 1923 and 1938 .

As the biscuit-patterned material covers rigid panels that both support the altered roof structure and impede its opening, it is evident that the roof structure as well as the interior upholstery must have been altered before 1938. It is also possible that, while the biscuit patterned material was not in the coach in 1923, the roof had been altered and rigid panels covered in another fabric had already been installed by this time.

In 1929, the coach was being stored and displayed in the open stables at Vaucluse House in Sydney [5], under an arrangement between the RAHS and Vaucluse House Trust. Vaucluse House curator, John Taylor, sent a letter [6] to the trustees of Vaucluse House suggesting an application of a leather dressing, varnishing of the body and ironwork, and installing blinds around the coach to

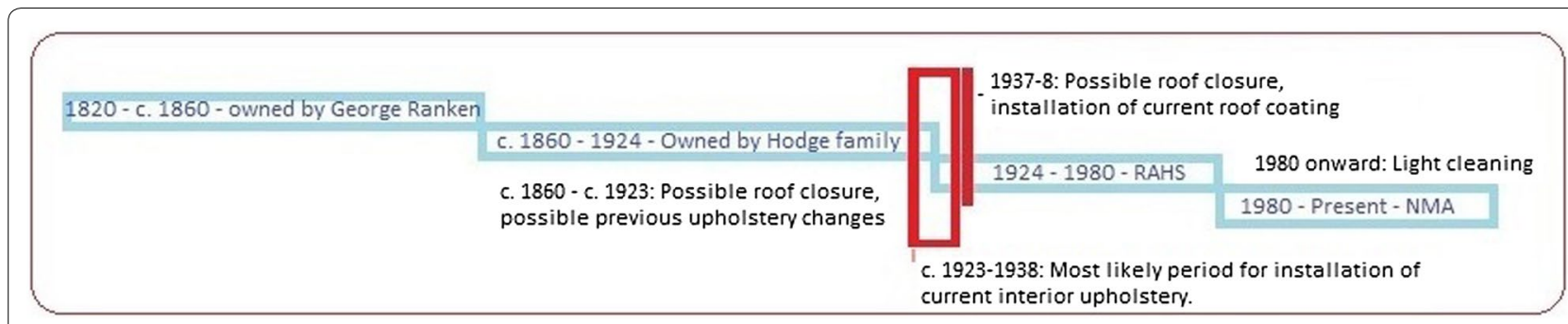

Fig. 1 Timeline showing ownership and hypothesised alterations of Ranken coach. Source: Ison 2015 


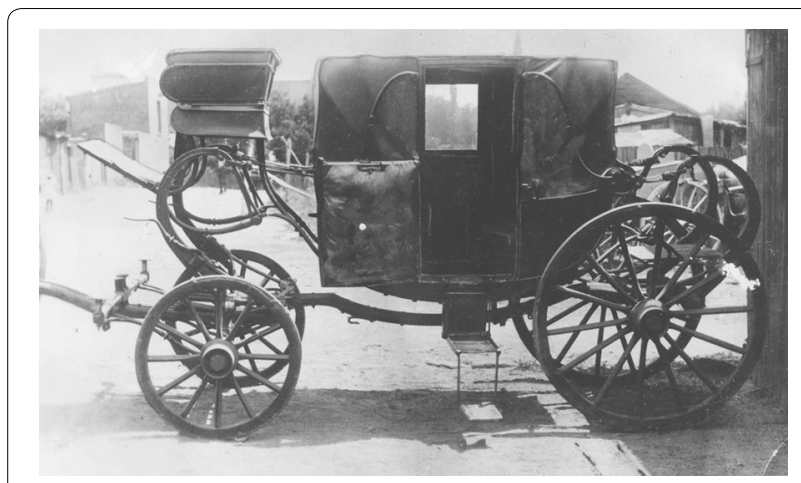

Fig. 2 Photo of the Ranken coach circa 1823. Reproduced with the permission of Bathurst District Historical Society (BDHS)

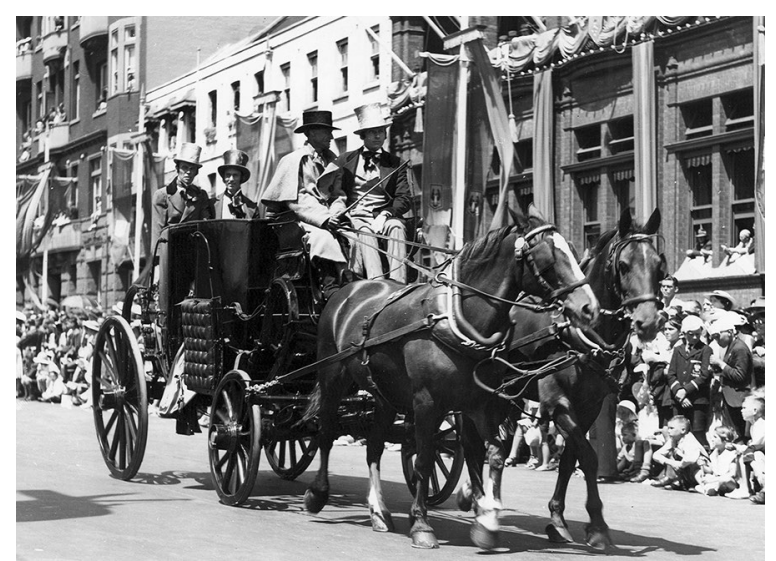

Fig. 3 Carriage in Procession in Macquarie Street Sydney, image number 20174-Ranken coach: "Australia's March to Nationhood". Reproduced with the permission of the RAHS

"protect the whole coach from the damaging effects of the sun". Hand writing on the bottom of this letter notes that these repairs were agreed to. This was followed up with a RAHS minute from 1930 [7] stating that the RAHS would contribute half of the $£ 15$ required to carry out the works. Unfortunately no documents exist to confirm either whether the Vaucluse Trust agreed to this arrangement, or whether the works were actually carried out.

In 1937, a minute of the RAHS stated that both the Ranken and another coach had been requested for participation in the Sydney sesquicentenary celebrations, and that this request would be approved "on condition that the coaches were first put in running order" [8]. Seven years had elapsed since work on the coach was previously discussed, so it is not possible to say whether work had been done in 1930 but continued exposure to the weather had returned the coach to a neglected condition, or whether no work had been done to improve the condition of the coach in the first place. K.R. Cramp of the RAHS contacted the Vaucluse Trust to request

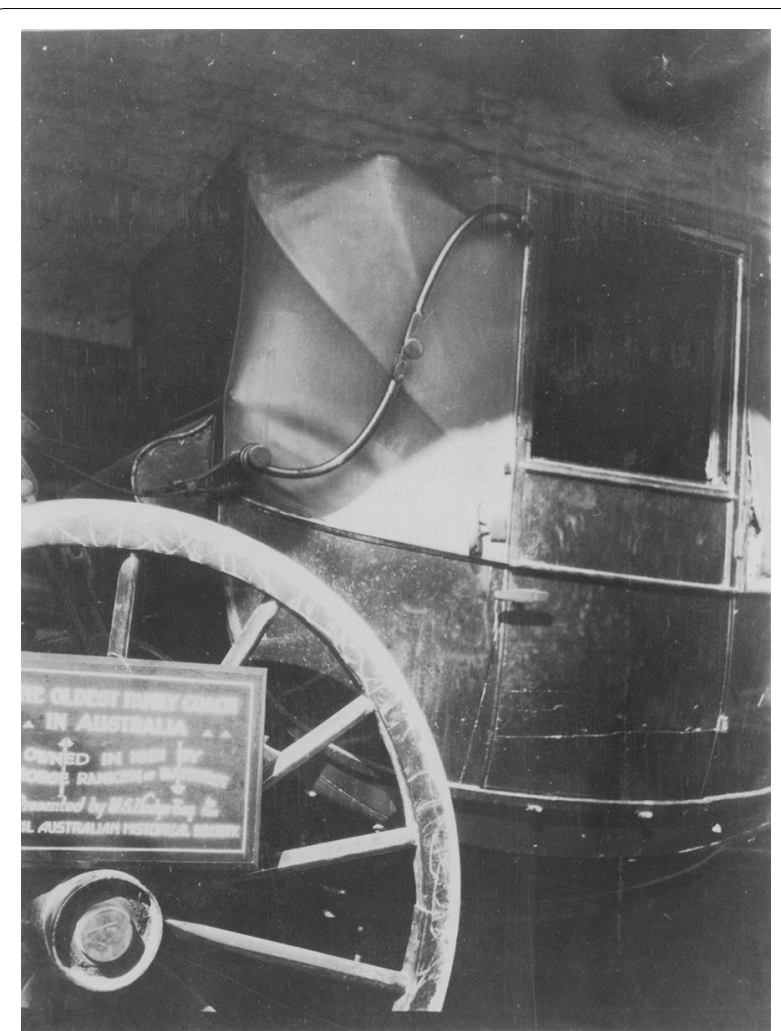

Fig. 4 The oldest family coach in Australia, 1927. Number 021/021621 - Reproduced with permission of the RAHS (image shows roof structure and tear in upholstery along door edge on far right of photograph)

an assessment of the coach's condition, and John Taylor, by this time the secretary for the Nielsen Park and Vaucluse Park Trust, instructed the Trust blacksmith to inspect the coach. Taylor's response to Cramp in 1937 included a copy of the blacksmith's report, which states that a "recovering and trimming of the external portions of the coach" would cost $£ 10$ [9]. This time it appears that work on the coach was done: an article appeared in the Mudgee Guardian and North-Western Representative newspaper declaring that the coach would be "refurbished" [10]; a further article two months later in the Cootamundra Herald stated that the coach was "practically good as new" [11], and the Ranken coach did make its appearance in the parade of the Sydney sesquicentenary celebration [4].

Photographs, believed to be from an earlier period than 1938, depict the coach in the stables at Vaucluse House (Figs. 3, 4). These photos show a torn edge of roof fabric close to the doorframe, and the outline of the landau bars are visible along the length of the material. In a photograph of the coach in the Sydney sesquicentenary parade, the roof appears to have a smoother line at the top, with the landau bars less prominent and some edge 
trim present. This strongly suggests that the roof coating present today was applied between May 1937 and January 1938 while the coach was in the possession of the RAHS, to improve its appearance and robustness for the sesquicentenary parade. There is no mention of the interior upholstery in the RAHS documents, so the date for the reupholstering of this portion of the coach has not been confirmed (Fig. 5).

There are no further references to alterations or repairs to the coach while it was in the RAHS collection.

The coach was acquired in 1980 by the NMA and in 1983 the first professional conservation assessment of the coach was undertaken. This report noted that the coach has been "extensively rebuilt/altered from original form" [12], while a minute produced in 1980 declared that the coach had "had some modifications made around the turn of the century, when the vehicle was converted for use as a mourning coach" [13]. The 1983 condition report states that the roof coating is of a different composition to that of the rest of the upholstery (that is, that of the back roll, front seat cushion and interior), and that the rest of the upholstery material is "older". However, there is no reason given for this conclusion other than the conservator's visual assessment [12].

The historical research therefore suggests that the roof coating and interior upholstery visible today date from between 1923 and 1938, and were applied either separately or together by either the Hodge family or the RAHS.

\section{Development and use of coated fabrics over the period of interest}

Literature from several subject areas was consulted to identify the likely chemical constituents of coated materials used in the late nineteenth and early twentieth centuries. This was useful to guide instrumental analysis;

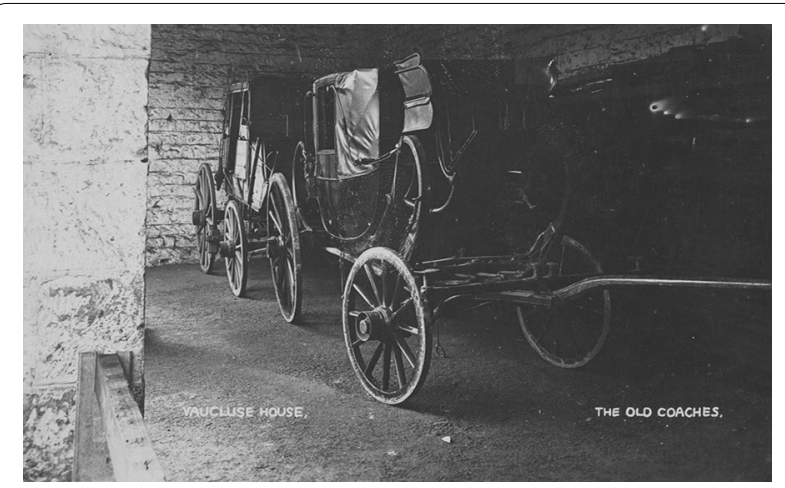

Fig. 5 Postcard depicting the Ranken landau coach at Vaucluse House prior to acquisition by the NMA in about 1980. Reproduced with permission from NMA, Historic Horse Drawn Vehicles archive collection no. 1, NMA identify the products that were considered, at the time, to have suitable properties for upholstery (in terms of availability, workability, cost, performance and appearance); and suggest any differences that might have existed in product availability and use in Australia as opposed to other countries. Research suggested that the coatings used on the Ranken coach were most likely to be based on, or include, India rubber, cellulose nitrate, cellulose acetate, or alkyds, or mixtures of these materials.

\section{Rubber as a coating material}

Adams [14] writing in $1837,{ }^{1}$ stated that India rubber, or Caoutchouc, was used in carriage building where pliability and waterproofing were needed. He mentioned that certain versions of this product were not as strong as others, and that "it is not so efficient, and wears away very rapidly" [14]. He warned that the coating deteriorates with contact with oil or grease, and it is "impossible to use it much for inside work, as the odour, especially in warm weather, is very unpleasant" [14]. While Adams appears disparaging towards this material, Edwards [15] discusses this rubber coating being applied to cloth in the mid 19th century, and calls it "Morocco cloth" stating that it was "clearly considered a suitable material" as a substitute for Morocco leather. There is also a recipe for a rubber and drying oil mixture for waterproofing materials in the 1883 Spon's recipe book [16].

\section{Cellulose nitrate as a coating material}

Cellulose nitrate was first made into a lacquer by Alexander Parkes when, in 1856, he patented the process of waterproofing woven fabrics with his product Parkesine [17]. Both Parkes in England, and John Wesley Hyatt in the United States, registered cellulose nitrate-based products which used camphor as the plasticiser, although previously in 1865 Parkes used castor oil in the mixture [18]. Materials developed from these products were adapted for making coated fabrics, including some of the first successful imitation leathers-which often were referred to under the descriptor of "leathercloth". Adrosko [19] states that leathercloth was "made on a plain woven cotton base, had a surface coating designed to resemble leather" and that it was called American Cloth in England, and Enamelled or Oil Cloth in the United States. McLintock [20] mentions "Zapon", a cellulose nitrate varnish made by Ioco Ltd, and a product called "Rexine", made by Imperial Chemical Industries Ltd, which he describes as "perhaps the best-known of all leathercloths" and which, at the time he was writing, had been in use for more than 50 years. Cellulose nitrate was also used as a varnish, or

${ }^{1}$ Adams's piece of writing was originally published in 1837, and is referenced from a reprint dated 1971. 
"dope", for stiffening and waterproofing fabrics used on aircraft [21], and Powers [22] states that polyester resins were sometimes used in lacquers in combination with cellulose nitrate.

\section{Cellulose acetate as a coating material}

Cellulose acetate was initially produced by Schutzenberger in 1865 , but not commercially distributed for a number of years after this date. The production method was similar to that for cellulose nitrate, using acetic anhydride instead of nitric acid [23]. Developed primarily as a solution to the problem of the flammability of cellulose nitrate, variations of cellulose acetate were introduced in 1894 and 1903. It was widely used from 1909 as a replacement for cellulose nitrate film and the first patent using it to impregnate paper and cloth for waterproofing purposes was granted in 1910.

At the end of World War One, cellulose acetate was also used as a replacement for cellulose nitrate for doping on aircraft [24] and it continued to be developed into new products with the introduction of fibres and moulded forms $[25,26]$.

\section{Alkyd as a coating material}

The first alkyds were invented in 1901 and were a combination of glycerol and phthalic anhydride mixed with a drying-oil fatty acid, such as linseed oil [27]. From this combination, further alkyd recipes were developed and by the late 1920 s, oil-modified polyesters had become commercially important to the varnish industry [28].

Ploeger and Chiantore [29] explain that there are different types of alkyd resin based on their oil content (or oil length) as this dictates different physical properties, and therefore different applications. Short oil compositions will dry faster and be more brittle than long oil [28]. Ploeger and Chiantore describe long oil alkyd resin's chemical structure as being represented by characteristic FTIR peaks, but they also state "pigments, extenders or fillers, and other additives can complicate spectral interpretation and must be taken into consideration" [29].

\section{Coating mixtures}

It should be noted that, in the period of interest, coating materials such as those discussed above were often mixed according to personal or local recipes, with a degree of experimentation. Examples include Spon's rubber and drying oil mixture mentioned above, and a 1930 recipe for reconditioning cracked and faded fabric bodywork that consisted of half a pint of boiled linseed oil and $2.5 \mathrm{oz}$ of shellac dissolved in methylated spirits [30].

This use of mixed compounds may be particularly relevant given the suggestions in the historical references that the Ranken coach fabrics were "varnished" to improve appearance and weatherproofing.

\section{Physical analysis of the coated fabrics on the Ranken coach}

This section will briefly describe the physical analyses performed on the coating samples from the coach, and then present an overview and discussion of the results of these tests for the interior upholstery and roof coating samples respectively. Further details of instrumentation and procedure are presented in the "Methods" section at the end of the paper.

\section{Preliminary tests}

UV light was used to analyse the fluorescence of different known coatings and compare them to the fluorescence of the unknown coatings on the Ranken coach, following the procedure described by Davies [31]. Observing how the coatings behaved when brought into contact with solvents was also used to support or rule out particular compositions. The diphenylamine spot test as described by Brunn [32] and Shashoua [18] was used to confirm the presence of nitrates.

\section{FTIR analysis}

Preliminary testing of the interior upholstery using FTIR to identify characteristic organic molecules was conducted during treatment in 2012, and proved inconclusive. FTIR was used because it can identify functional groups in organic compounds, and the Ranken coach's coated materials were thought to be synthetic. FTIR testing was conducted again in 2014-2015 using instrumentation and software that allowed more in-depth analysis of the results.

\section{Py-GC-MS analysis}

Caple [33] lists FTIR as a suitable mode of analysis for single component organic compounds. He also recommends varieties of chromatography for mixtures of organic compounds. As it was not known whether the coatings on the coach were single or multiple component organic compounds, Py-GC-MS was conducted to complement the FTIR results.

\section{Interior upholstery \\ Preliminary tests}

The interior upholstery samples were removed from the seats while they were being cleaned. It has been assumed that the padded walls and the falls at the front of the seats are made of the same material.

Visual examination showed that the substrate is a woven material which indicates that this is a relatively early type of coated material (Fig. 6). Doyal mentions 


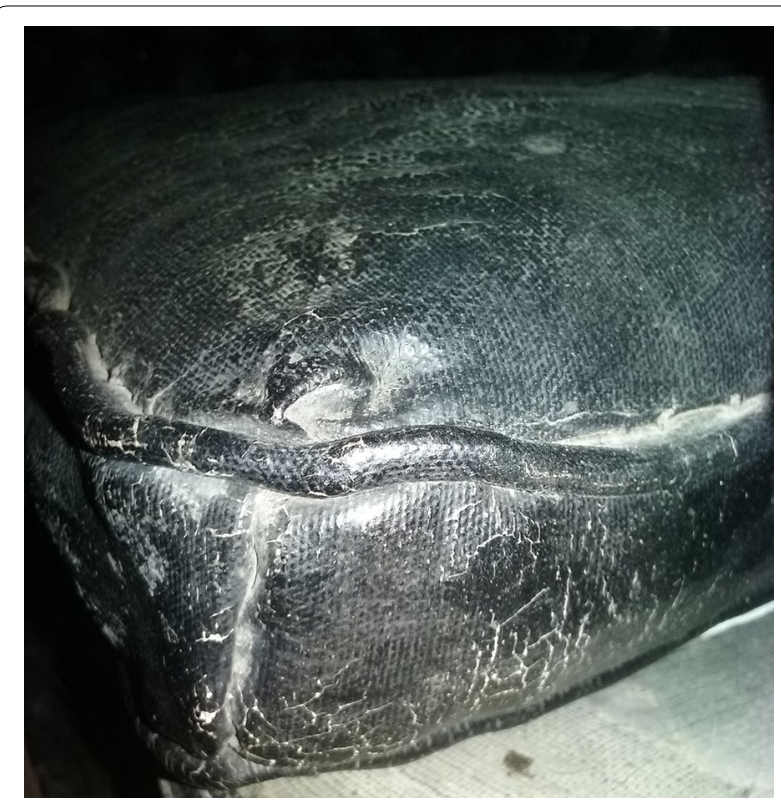

Fig. 6 Photo of seat of Ranken coach showing evidence of woven substrate and repeating surface pattern. Source: Ison 2015

that woven substrates were eventually replaced in the twentieth century by knitted fabric because "less skill is required in the application of these [knit] fabrics" [34].

Coatings can be applied in many different ways. Earlier coatings on fabrics were painted on with a brush or applied by "dipping the article to be coated in a bath of liquid resin" [21]. Roller-coating methods were developed and refined from as early as the 1820s [35], eventually enabling bulk production of continuous rolls of coated fabric. Roller-coating systems are highly controllable, accurate and reproducible [36] and provide the opportunity to apply a repeating pattern to the coating, such as a leather-look grain. The interior upholstery on the Ranken coach appears to have a repeating dot-like surface pattern applied which suggests that the coating was likely to have been applied using a roller-coating process.

Under a microscope, the interior upholstery coating samples appear thick and brittle. While the main body of the cross-section appears homogeneous, smooth and glass-like, there is a distinctly different surface layer. This surface layer appears to have shrunk at some point, suggesting that some loss has occurred, or that the surface has contracted more quickly than the rest of the coatingpossibly due to a drying process where the surface forms a skin. This detail is shown in Fig. 7. All surface layers on every sample contain dirt and small embedded impurities.

There are also lighter grey/white areas visible on some of the sample surfaces. This grey/white substance could be a finishing or dressing product, an exudate from the coating or a by-product of a deterioration process.

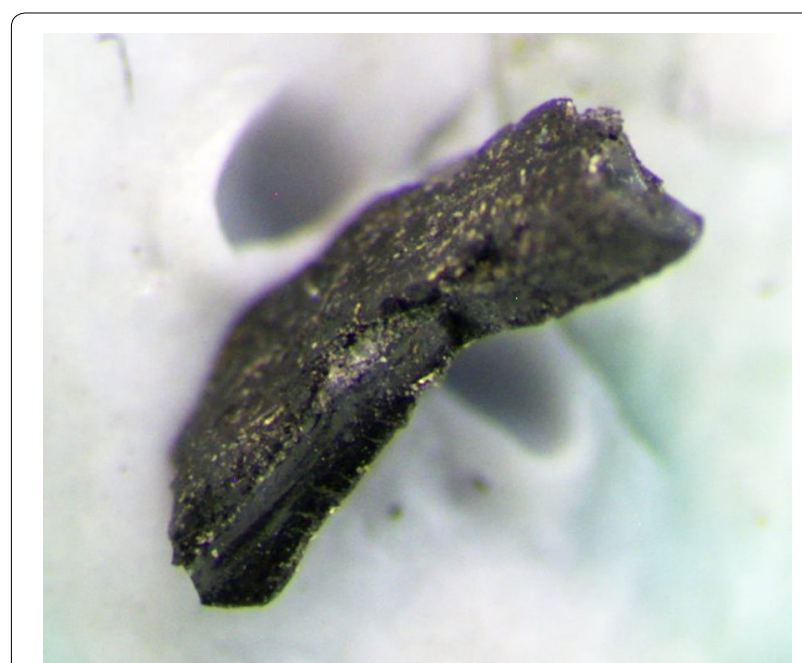

Fig. 7 Microscope photograph of piece of interior upholstery on cross-section showing contracted surface and smoother main body. The sample is approximately $3 \mathrm{~mm}$ wide. Source: Ison 2015

Solubility tests in 2012 showed that the seat coating dissolved in acetone and fragmented when exposed to ethanol, but did not react to petroleum spirits. A repeat of this test in 2015 on a different sample found that the coating did not dissolve in either acetone or white spirits. This suggests that the piece which dissolved in acetone in 2012 may have been part of a topical treatment or surface layer as opposed to the homogenous body of the coating. A diphenylamine test was conducted and there was no dark blue colour change, confirming that this particular sample of material does not contain nitrates and is therefore unlikely to be cellulose nitrate.

\section{FTIR}

The FTIR tests obtained in 2014 at the Museum of Applied Arts and Sciences (MAAS) and in 2015 at The National Centre for Forensic Studies (NCFS) at the University of Canberra (UC) produced largely similar spectra. However, there are slight discrepancies between the spectra in the region between $\sim 1710$ and $650 \mathrm{~cm}^{-1}$. When the spectra were compared to polymer libraries at MAAS and NCFS, the suggested matches included respectively shellac, and alkyds with varying combinations of oils and anhydrides. The NCFS spectra are shown in Fig. 8.

These variations in the spectra support the interpretation that there are multiple materials within the sample bag, and that the coating could be a combination of ingredients, as discussed in the section on "Coating mixtures". It was also noted that there were peaks at around the 3700-3600 and $1050-900 \mathrm{~cm}^{-1}$ regions which are found in spectra for calcium carbonate and calcium sulphate. Peaks in this region 


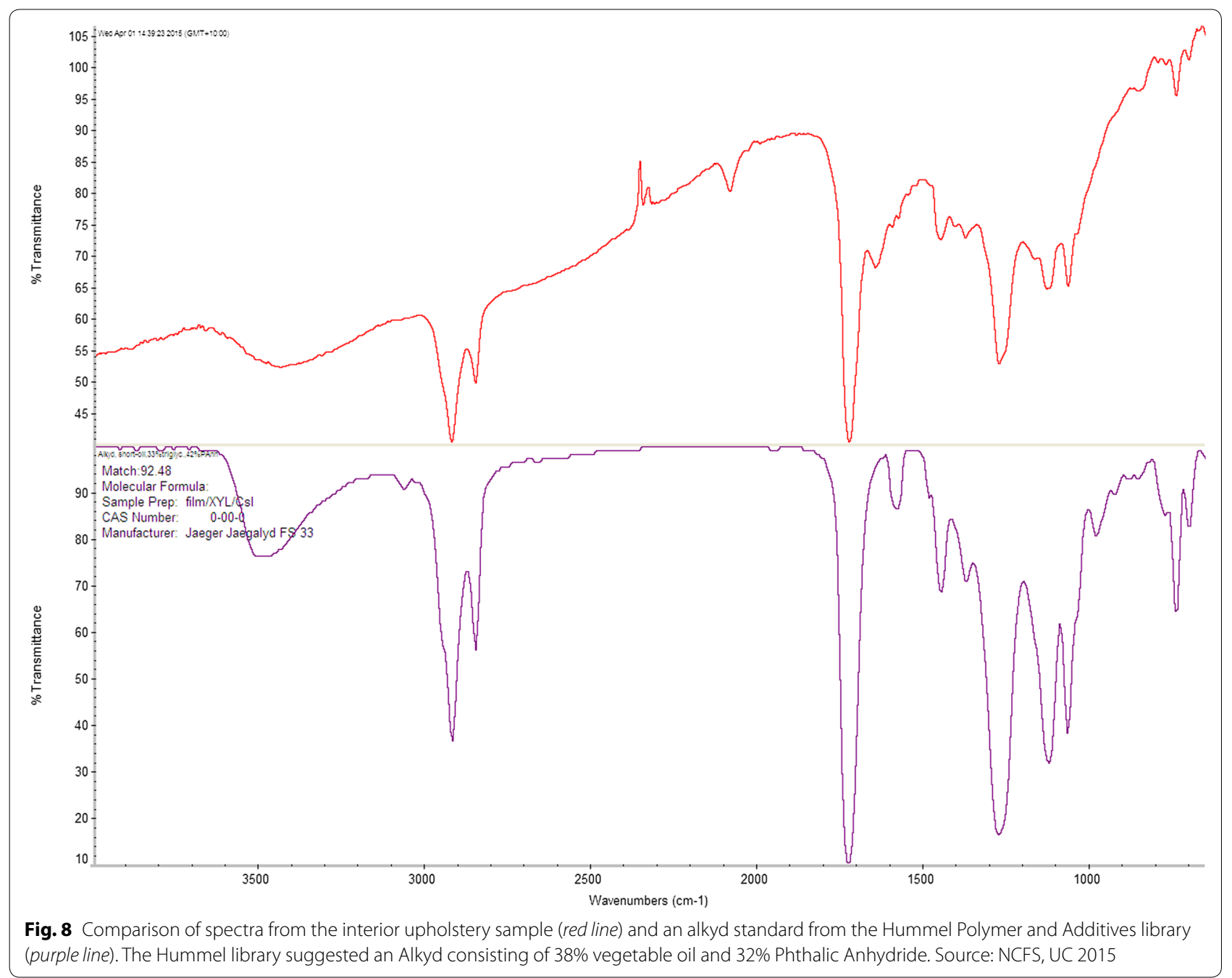

corresponding to the presence of kaolin were detected in the 2012 and 2014 spectra taken on an instrument at the National Archives of Australia (I. Batterham, personal communication, 8 December 2014). Kaolin and other mineral compounds are sometimes used as fillers in plastics [37], so it is not surprising to find them in the Ranken coach sample. These mineral peaks can obscure other diagnostic bands within the sample, which may also account for some of the variation between the Ranken sample spectrum and the alkyd spectrum (R. Goodall, Museum of Victoria, personal communication, 3 August 2015).

\section{Py-GC-MS}

Alkyd resins can be identified in Py-GC-MS spectra by the presence of compounds including benzoic acid, pentaerythritol, phthalic anhydride and various fatty acids derived from the oil used in the manufacture of the alkyd [38]. The thermally assisted hydrolysis and methylationgas chromatography-mass spectrometry (THM-GC-MS) conducted by Ploeger and Chiantore [29] refers to peaks including phthalic acid, palmitic acid, oleic acid, stearic acid and phthalate plasticiser. The precise range and quantity of compounds found in any one alkyd sample will depend on the compounds used its manufacture and the degree to which the alkyd has been aged [38] but if the interior upholstery sample was of an alkyd construction, similar components would be expected in the results.

Common peaks were found in several of the spectra. Details of the compounds identified in the individual Py-GC-MS tests are presented in Table 1.

Phthalic anhydride was present in both tests seven and nine. Its position in the results at different retention times is due to the difference in the temperature ramp rate for these two tests. The presence of phthalic anhydride supports the hypothesis that this coating is an alkyd given that phthalic anhydride is a principle constituent in the composition of alkyds. According to Wei et al. [38] 


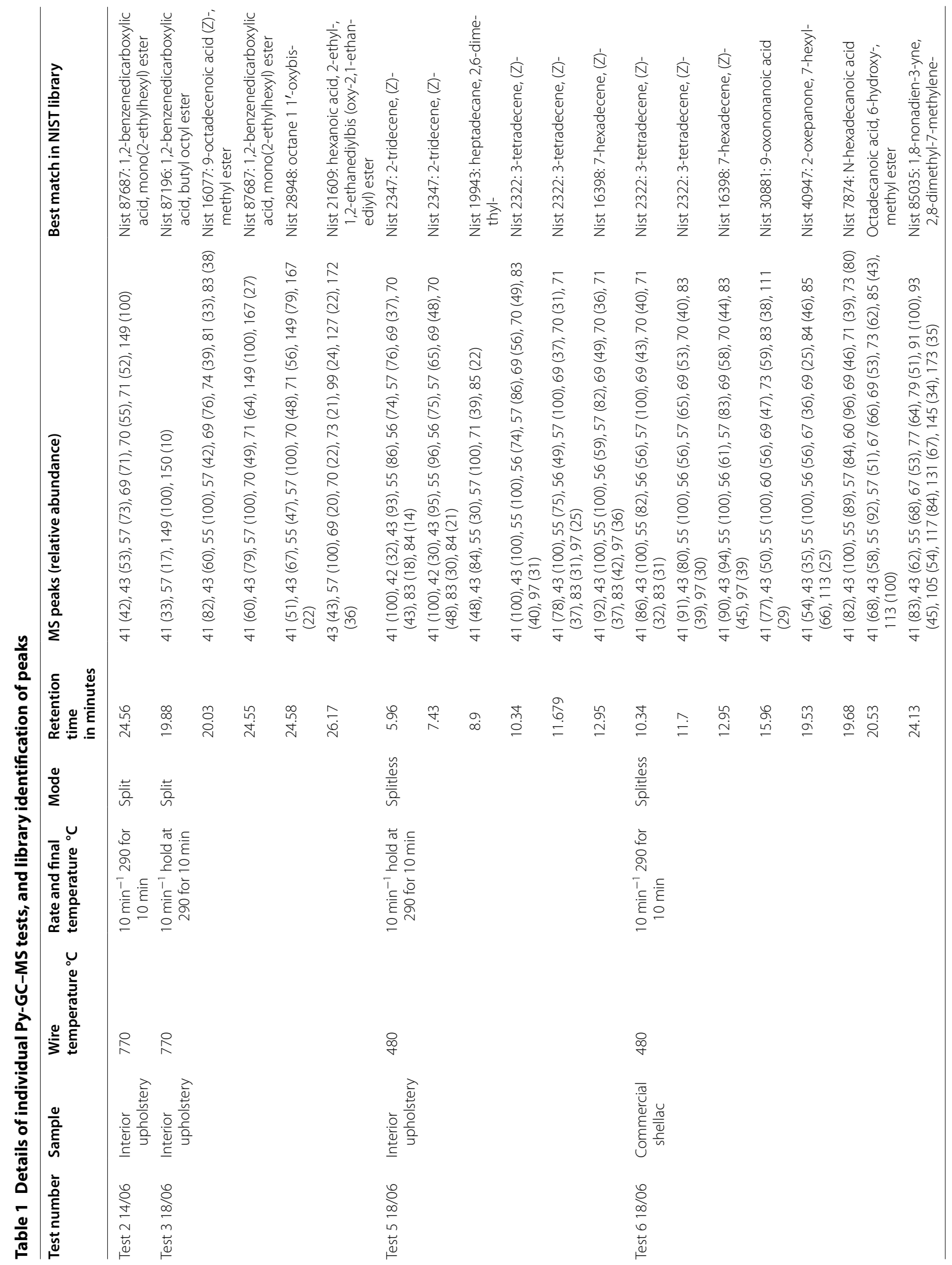




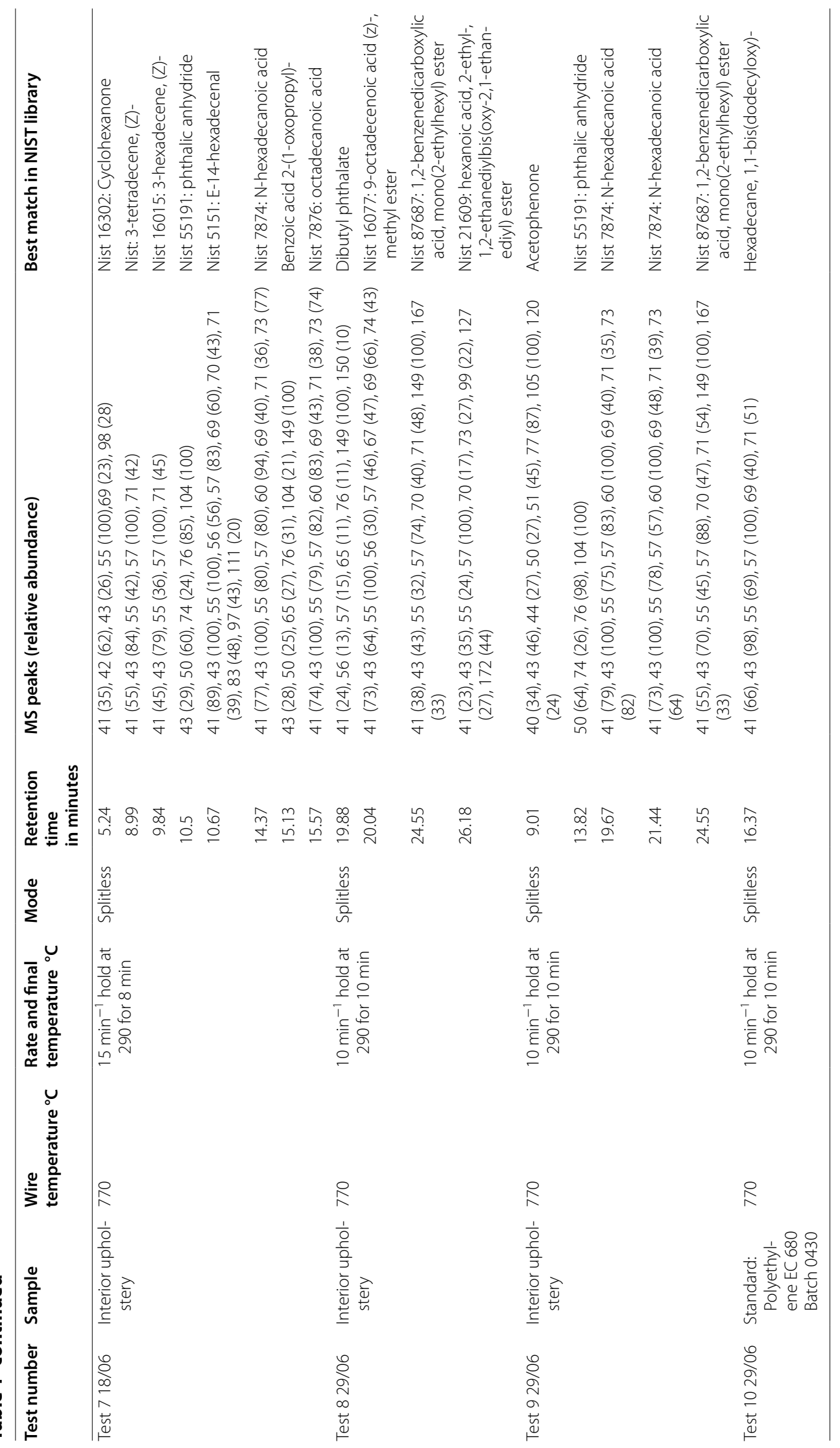


the amount of phthalic anhydride increases with aging of the sample. Phthalic anhydride did not appear in every sample, and reasons for this could be due to the small sample size collected and analysed and the potential heterogeneity of the samples, which is discussed in more detail below and in the "Coating mixtures" and "Preliminary tests" sections above.

In other tests, the library returned top hits for octadecanoic acid and n-hexadecanoic acid, which are both fatty acids and are likely to appear in an oil-modified alkyd.

There were common peaks in several of the spectra at the 24.55 min mark (or equivalent in tests with shorter retention times). These peaks varied in size but produced a number one hit in the NIST mass spectra library for the phthalic acid ester, 1,2-benzenedicarboxylic acid, mono (2-ethylhexyl) ester (MEHP). Its presence could represent an impurity in the column [39], but as it appears in different quantities throughout the samples, it could also be a component of the sample or a by-product of the aging process.

In test three and eight (Fig. 9), there were peaks in common in the $19.88 \mathrm{~min}$ region, which produced a number one hit for dibutyl phthalate in the NIST mass spectra library for test eight and 1,2-benzenedicarboxylic acid, butyl octyl ester for test three. These substances are both used as plasticisers. Ploeger and Chiantore do not specify the type of "phthalate plasticiser" found in their samples, but the presence of these phthalate plasticiser matches strongly suggest that the interior upholstery samples, while likely consisting of a mixture of different substances, contain the types of compounds which would be present in an alkyd coating.

Test three and eight also produced number one hits in the NIST mass spectra library for the fatty acid 9-octadecenoic acid (Z-), methyl ester, and hexanoic acid, 2-ethyl-,

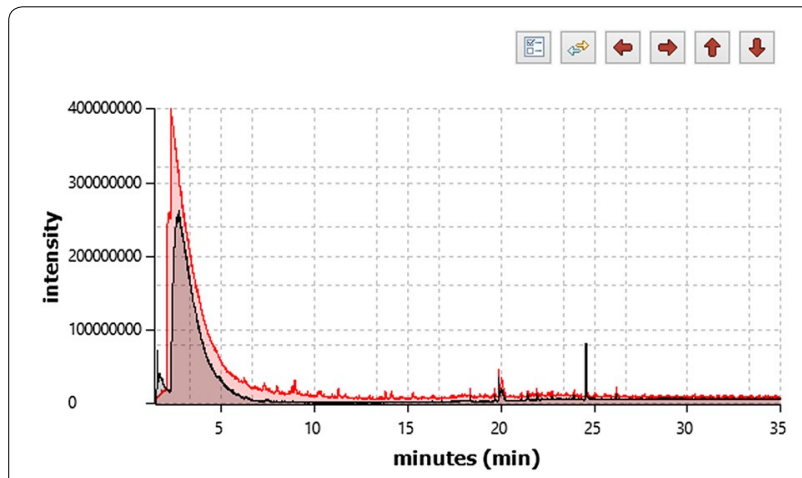

Fig. 9 Gas Chromatogram of sample showing test three (black line) and test eight (red line). Source: NCFS, University of Canberra, 2015. Open Chrom software, 2016 1,2-ethanediylbis(oxy-2,1- ethanediyl) ester, which is a plasticiser used today in polyvinyl chloride (PVC) [40].

The obvious relationships to compounds used in contemporary PVC raised the question as to whether the coating in the samples is actually PVC. While PVC existed in 1938, flexible (plasticised) PVC-coated fabrics were not widely commercially available until after World War Two [25] and historical evidence shows that the recovering of the Ranken coach was completed by 1938 . The FTIR spectrum of the interior coating was compared to the FTIR coating of plasticised PVC provided by Verleye et al. [41] and the spectra were found to not be a match. It is possible that the coach samples are historic formulations containing substances similar to those used in modern plastics, which do not have exactly equivalent NIST library reference spectra.

Earlier FTIR results had returned shellac as a possible match, so a sample of commercially-available shellac was compared with a sample of the interior upholstery using Py-GC-MS. While the two samples shared some common peaks, the spectra were different, with some peaks unique to each sample. There were no library matches in either sample for markers specific to shellac, including shellolic, laccishellolic, aleuritic and butolic acids. The use of Py-GC-MS without derivatisation reportedly results in less successful outcomes due to the appearance of "numerous hydroxy and carboxylic acid groups in the lac constituents" [42]. As a result, further research is needed to confirm or reject the presence of shellac as an ingredient in the sample.

The variation in the results from the different tests suggest that the samples represent a heterogenous coating; possibly a topical coating, plus an internal layer. However, many of the compound hits for the mass spectrometer were fatty acids, phthalic esters, or acids and anhydrides, strongly suggesting that the interior upholstery coating contains an alkyd. Although every interior upholstery sample analysed had a different combination of the above ingredients, Ribechini et al. discuss that pyrolysis of "acyl-lipid" material can be complex and mixtures can produce results difficult to analyse [43].

\section{Roof coating Preliminary tests}

The roof coating samples were taken from the exterior section of the roof coating. It has been assumed that the interior roof coating (on the ceiling of the vehicle), and the exterior roof coating (including the sides and top of the vehicle) are of the same material.

Visual examination showed that the substrate is a woven material, which again indicates that this is an early type of coated material (Fig. 10). The coating is of a slightly shinier black appearance than the interior 


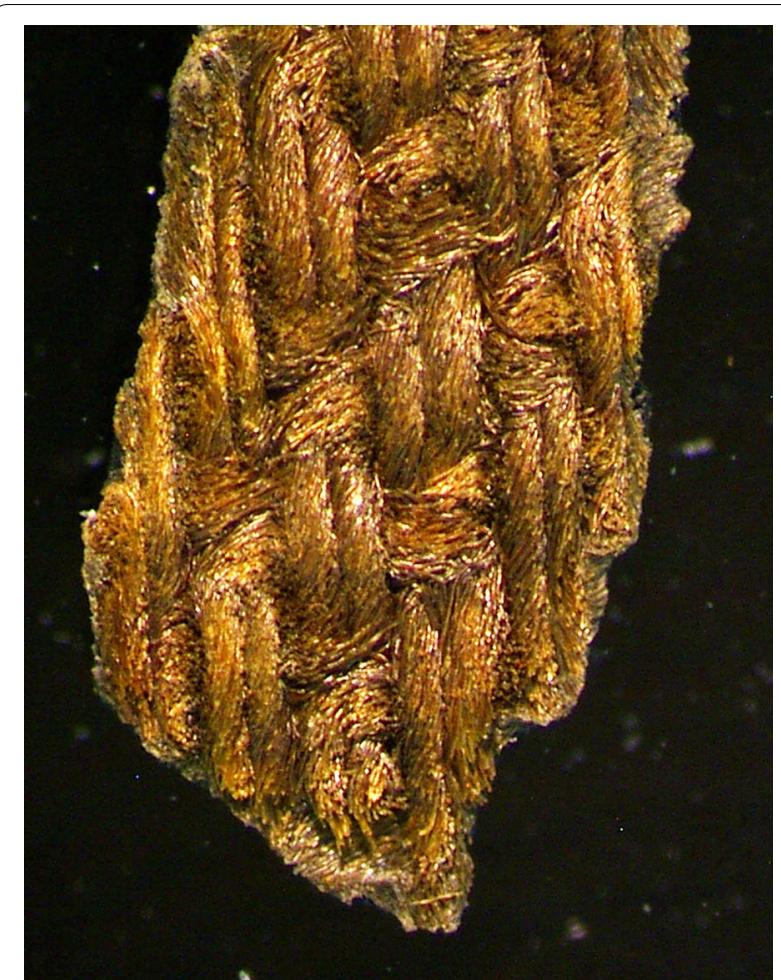

Fig. 10 Substrate of roof coating under microscope. The sample is $8 \mathrm{~mm}$ long. This microscope photo shows a $4 \mathrm{~mm}$ section of the $8 \mathrm{~mm}$ length. Source: Ison 2015

upholstery, and is applied in a smooth layer less than $1 \mathrm{~mm}$ thick. The woven substrate is brittle and there are areas where the coating has also become brittle-particularly around the rusted brackets, which close the landau hood (the roof coating samples were removed from this area).

A cross-section (Fig. 11) shows that the coating is embedded into the woven substrate. Visual examination showed that there is a difference in thickness between the roof coating and the interior upholstery, and a difference in the attachment to the substrate. These differences may be due to the use of different rolling conditions including different apparatus, drying times, consistencies, or other factors.

On the upper surface of the coating, there appears to be light and dark components, and under magnification (Fig. 12), it appears that the darker layer is a very thin black coating on top of a lighter-coloured surface. As with the interior upholstery, all surface layers on every sample contain dirt and small embedded impurities.

The black areas of this coating did not fluoresce under UV light, but the lighter material did. This suggests that the dark black is a topical coating of a different substance.

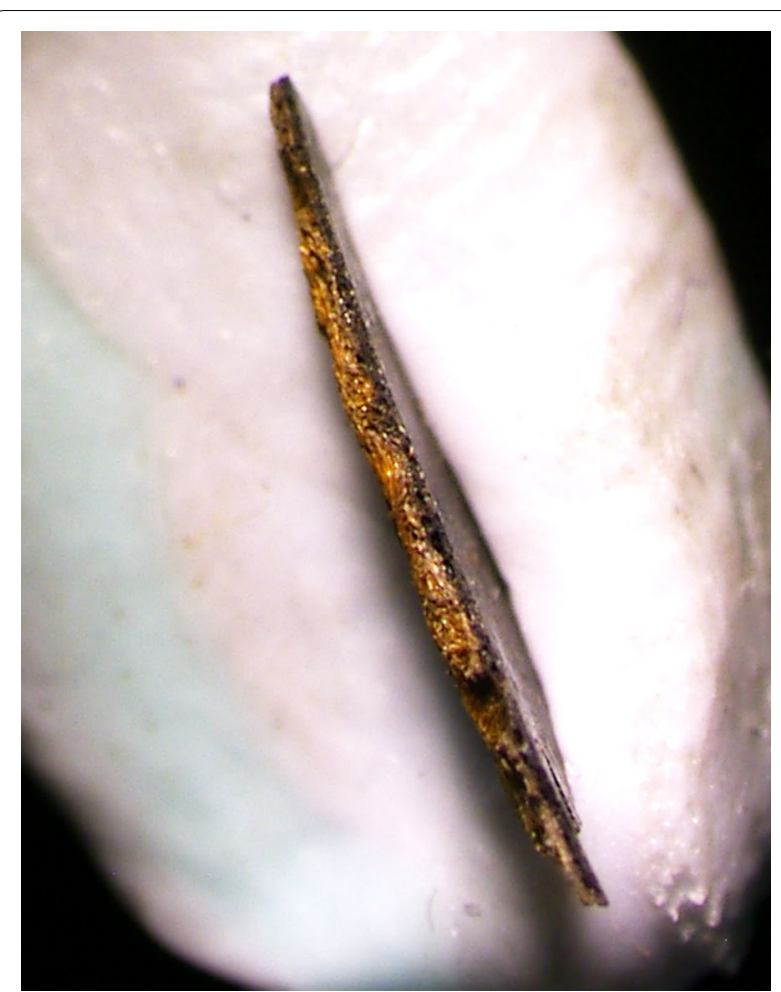

Fig. 11 Cross-section of roof coating. Sample is approximately $6 \mathrm{~mm}$ long. Source: Ison 2015

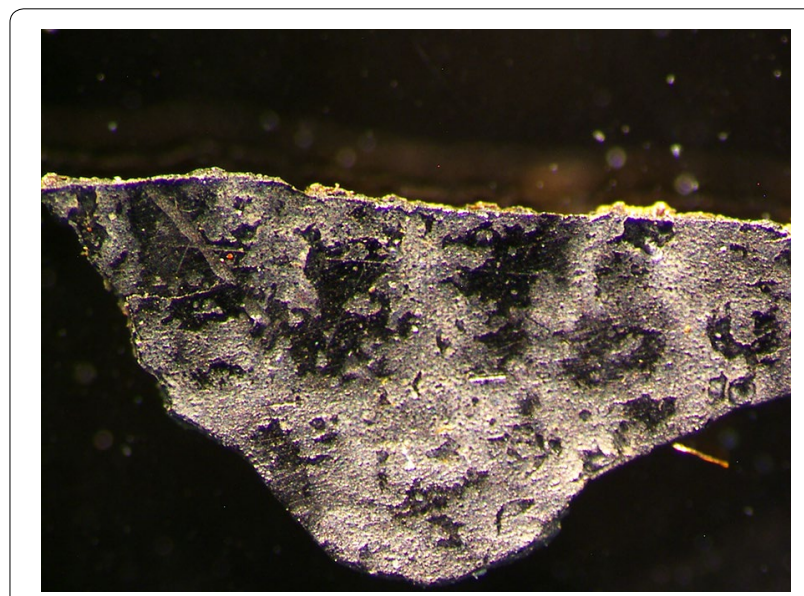

Fig. 12 Cross-section of roof coating showing light and dark surfaces. The area shown is $4 \mathrm{~mm}$ in length. Source: Ison 2015

The roof coating was found to dissolve in acetone. The roof coating also returned a colour-change on the diphenylamine test confirming that nitrates were present on the sample tested. Both of these results suggest that the material is composed of cellulose nitrate. 
FTIR

The spectra from the 2014 (MAAS) and 2015 (UC) FTIR tests of the roof coating displayed similar peaks and were suggestive of cellulose-based compositions. Figure 13 shows the UC spectra returning a match for cellulose nitrate.

Peaks characteristic to cellulose nitrate appear at 3400, 3000-2840, 1654, 1279, 1063 and $841 \mathrm{~cm}^{-1}$ [41]. The peaks on the MAAS and UC spectra appear close to these points. As the results from the FTIR testing of the roof coating strongly suggest that the coating is a cellulose nitrate product, further testing with Py-GC-MS was not used as it was unlikely to contribute additional information to the identification process. Learner states that cellulose nitrate "gives a featureless pyrogram" [44] and Quye and Williamson state that cellulose acetate and nitrate do not yield good Py-GC-MS results [26], possibly because of the small size and the simplicity of the cellulose nitrate molecule.

\section{Conclusion}

The dates at which the Ranken coach was altered and reupholstered in new coated fabrics cannot be definitively established. Historical research shows, however, that the alterations to the roof structure and the installation of the current exterior roof coating must have occurred before 1938, and that the current interior upholstery must have been installed between 1923 and 1938. RAHS records and contemporary newspaper articles strongly suggest that at least some of this work was undertaken between May 1937 and January 1938 in order to prepare the coach for the Sydney Sesquicentenary celebrations in 1938.

Physical analysis of the interior upholstery material, including visual examination under magnification, solubility tests, FTIR, and Py-GC-MS, suggest that it is an alkyd material. Alkyd coatings were invented in 1901 and had become widely used as surface coatings by the late 1920 s, so it is quite possible that an alkyd-coated fabric

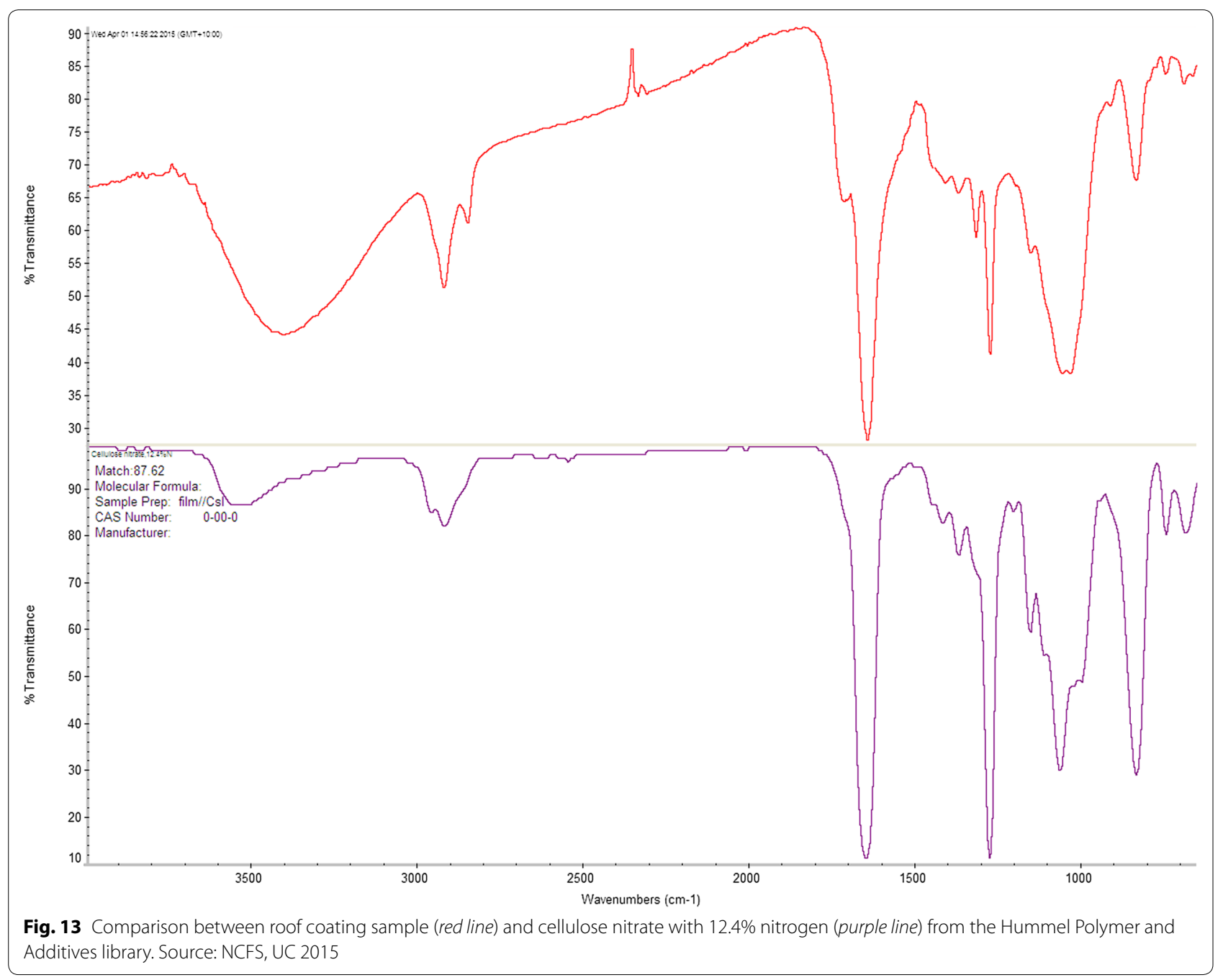


could have been used on the coach between 1923 and 1938. Visual examination also suggested that the material had had an additional topical coating applied, either when it was installed or at a later date and probably to improve either its look or weatherproofing performance. It was not possible, however, to identify the nature of this topical material in more detail in this study.

Many of the compounds detected in the interior upholstery sample, while very similar to compounds used in alkyd formulations today, were not exact matches to current NIST library standards. This research was unable to establish whether this was because early alkyd formulations used slightly different compounds as plasticisers and other coating components to those used today, or whether ageing processes have subtly altered the original components. Literature on early coating manufacturing and use practices, as well as comments in the correspondence regarding repairs to the coach, also strongly suggest that manufacturing processes could be quite variable, that coatings were sometimes mixed with additional compounds such as shellac and linseed oil to adjust their working properties or performance, and that additional topical applications could be applied to protect or "rejuvenate" existing coated fabrics after their initial installation. It is likely that a combination of these factors has produced the particular range of compounds seen in the analyses of the interior upholstery.

Physical analysis of the roof coating material suggests that it was primarily composed of cellulose nitrate. This conclusion was supported by solubility testing, the diphenylamine test described above, and FTIR instrumental analysis. Literature on the development of coated fabrics indicates that cellulose nitrate fabric coatings were in use in the 1920s and 30s, which includes the period in which structural and cosmetic repair works on the coach were approved by the RAHS in order to make it ready for the Sydney sesquicentenary celebrations in 1938. It is, therefore, quite possible for cellulose nitrate coatings to have been used on the coach at this point. Darker patches on the surface of the sample were apparent under both visible and UV light which suggested that, as for the interior upholstery, a topical coating may have been applied at some stage over the top of the coated fabric surface. As with the potential coating on the interior upholstery, however, it was not possible to identify the nature of this material in more detail in this study.

The Ranken coach was brought to Australia in the earliest period of European settlement. This makes it one of the oldest vehicles in Australian collections, and means that the materials and methods used to repair and update it reflect not only changes in fashion and its role and use, but also the uptake of emerging coatings and coated fabric technologies in Australia at this time.
Little is known about the use practices and composition of early coated fabrics found on actual historic objects. Information on the development of coating types and manufacturing techniques is available in literature on the development of the plastics industry, but this only tells us what could have been used, and in what approximate periods it is likely to have been used. It does not tell us what was used at a specific place and time, the application practices likely to have been used by the craftspeople doing the work, or the changes that the material they applied may have undergone since. To reliably tie broader histories of coating development to the use of those coatings in specific historical situations it is necessary to study the history and physical composition of actual objects from the past. In turn, this provides information that deepens the understanding and interpretation of such objects, and informs their future care. This is the aim of the current research on the coated fabrics used in the Ranken coach.

\section{Methods \\ FTIR}

The first FTIR spectroscopy was conducted at MAAS, Conservation Unit and carried out by Sue Gatenby on a Perkin Elmer 100 Spectrometer with Universal Attenuated Total Reflectance (UATR) accessory. The samples were analysed in transmission mode with the sample placed firmly onto the crystal for analysis. The spectra were acquired over a range of $4000-650 \mathrm{~cm}^{-1}$ using 30 scans at a resolution of $4 \mathrm{~cm}^{-1}$. The FTIR library in use to compare the spectra was Hummel Industrial Polymers Volume 1.

The second FTIR spectroscopy was performed at NCFS, UC, on a Nexus FTIR Spectroanalyser Thermo Nicolet with Continuum Thermo Spectra Tech IR microscope. A small sample was taken from the edge of the material and placed onto the crystal. A microscope was used to obtain the spectra. The spectra were acquired over a range of $4000-650 \mathrm{~cm}^{-1}$ using 64 scans. The software was Omnic v7.3. The FTIR library in use to compare the spectra was Hummel Additives and Polymers.

\section{Py-GC-MS}

The analyses of the interior upholstery samples were performed at NCFS, UC, on a Perkin Elmer Autosystem XL gas chromatograph (GC) with a Pyromat v. 1.07B curie point pyroliser coupled to a Perkin Elmer Turbo mass upgrade mass spectrometer (MS). The column used was an Agilent HP-5MS $30 \mathrm{~m}$ column $(30 \mathrm{~m} \times 0.25 \mathrm{~mm}$, $0.25 \mu \mathrm{m}$ film thickness) which had been reduced in length to approximately $25 \mathrm{~m}$ (this is done to improve the quality of the peaks by removing impurities that may be present in the first part of the column). The carrier 
gas was helium at $1 \mathrm{~mL} \mathrm{~min}{ }^{-1}$. It should be noted that the first five tests were performed in split mode, which was then changed to splitless for the remainder of the tests. As there were matching spectra from both modes, the results have been deemed to be comparable, and have been included in this discussion. Unless otherwise stated in Table 1 the temperatures are as follows: Manual injection used iron wires at $770{ }^{\circ} \mathrm{C}$. The initial oven temperature was set to $50{ }^{\circ} \mathrm{C}$ and held for $1 \mathrm{~min}$, then the temperature was ramped to 290 at $10{ }^{\circ} \mathrm{C}$ per minute, with the final temperature held for $10 \mathrm{~min}$. The MS interface temperature was $220{ }^{\circ} \mathrm{C}$. Data acquisition was undertaken in scan mode after a solvent delay of $1.5 \mathrm{~min}$. Turbomass v5.2 software was used for system control and data collection/manipulation. Mass spectral data were interpreted manually with the aid of the National Institute of Standards and Technology (NIST) Mass Spectral Library and comparison with published data.

\section{Abbreviations}

BDHS: Bathurst District Historical Society; FTIR: Fourier transform infrared spectroscopy; MAAS: Museum of Applied Arts and Sciences; MEHP: 1,2-benzenedicarboxylic acid, mono (2-ethylhexyl) ester; NCFS: National Centre for Forensic Studies; NIST: National Institute of Standards and Technology; NMA: National Museum of Australia; PVC: polyvinyl chloride; Py-GC-MS: pyrolysis gas chromatography mass spectroscopy; RAHS: Royal Australian Historical Society; THM-GC-MS: thermally assisted hydrolysis and methylation-gas chromatography-mass spectrometry; UC: University of Canberra; UV: ultraviolet.

\section{Authors' contributions}

Historic and physical research and initial analysis was carried out by NI. Final analysis and preparation of the manuscript was carried out by NI, AW and JH. All authors read and approved the final manuscript.

\section{Author details}

${ }^{1}$ National Museum of Australia, Canberra, Australia. ${ }^{2}$ University of Canberra, Canberra, Australia.

\section{Acknowledgements}

The authors would like to thank the National Museum of Australia; lan Batterham; Alana Treasure; Sue Gatenby and the Museum of Applied Arts and Sciences; Rosemary Goodall and Museum Victoria; and Shirani Katupitia and NCFS for their generous provision of time, access to equipment, and thoughtful comments.

\section{Competing interests}

The authors declare that they have no competing interests.

Received: 2 November 2016 Accepted: 10 February 2017 Published online: 03 March 2017

\section{References}

1. The National Museum of Australia. Horsedrawn Coach. National Museum of Australia. http://www.nma.gov.au/exhibitions/hall/horsedrawn_coach. Accessed 29 Jan 2017.

2. Burgess J. A practical treatise on coach-building. Liverpool: Dene Bindery; 1988. p. 12.

3. 102 years old. National Advocate. 11 June 1923. http://nla.gov.au/nla. news-article158688089. Accessed 29 Jan 2017.

4. Carriage in Procession in Macquarie Street Sydney, [Photograph]. 1938. Magazine of the Royal Australian Historical Society; 1990. p. 16.
5. MacDougall JC. Vaucluse house- to the editor of The Herald. The Sydney Morning Herald; 1929. p. 8. http://nla.gov.au/nla.news-article16590953. Accessed 29 Jan 2017.

6. Taylor J. For the gentlemen trustees of vaucluse Park Trust, December 5, 1929. Letter. National Museum of Australia. Royal Australian Historical Society Collection No 1-Ranken coach (File no. c1986.038-1).

7. Royal Australian Historical Society. Repair of "Old Family Coach" at Vaucluse House. Society minutes 1930, January 31. History House, transcribed by D. Newton.

8. Royal Australian Historical Society. Loan of Rankin[sic] Coach and Cobb and Co-Coach for Anniversary Celebrations. 1937, May 14. History House, transcribed by D. Newton.

9. Taylor J. Letter to K.R. Cramp, Esq., October 12, 1937. Letter. National Museum of Australia. Royal Australian Historical Society Collection No 1-Ranken coach (File no. c1986.038-1).

10. Ancient Coach. Mudgee Guardian and North-Western representative; 1937. p. 12. http://nla.gov.au/nla.news-article162499524. Accessed 29 Jan 2017

11. Family coach sent twice to Australia. Cootamundra Herald. 1938. p. 2. http://nla.gov.au/nla.news-article139954556. Accessed 29 Jan 2017.

12. The National Museum of Australia: M of A Conservation-Ranken coach built 1821: 1983/71: Canberra; 1983: Brief description Para. 1.

13. The National Museum of Australia: Royal Australian Historical Society Collection No 1-Ranken coach: c1986.038-1: Canberra; 1986: p. 38.

14. Adams WB. English pleasure carriages. 1971 ed. Bath: Adams and Dart; 1837: p. 80, 252

15. Edwards C. Encyclopedia of furniture materials, trades and techniques. Aldershot: Ashgate; 2000. p. 60.

16. Spon E, Haldane R, Lock C. Workshop receipts: London: E. \& F.N. Spon; 1883. p. 71. https://openlibrary.org/books/OL22896864M/Workshop_ receipts. Accessed 25 Jan 2017.

17. Brydson JA. Plastics materials Fourth. London: Butterworth Scientific; 1982. p. 662.

18. Shashoua Y. Conservation of plastics. Oxford: Butterworth-Heinemann; 2008.

19. Adrosko RJ. Identifying late 19th-century upholstery fabrics. In: Williams $\mathrm{M}$, editor. Upholstery conservation: preprints of a symposium held at colonial Williamsburg February 2-4, 1990. East Kingston: American Conservation Consortium, Ltd.; 1990. p. 103-135, 109.

20. McLintock JD. Modern coach and motor trimming. London: The Technical Press Ltd; 1951. p. 19.

21. Wordingham JA, Reboul P. Dictionary of plastics. 1st ed. London: George Newnes Limited; 1964. p. 54.

22. Powers PO. Synthetic resins and rubbers. New York, London: Wiley, Chapman \& Hall, Itd; 1943. p. 238

23. Seymour R. Origin and development of polymeric coatings. In: Seymour $\mathrm{RB}, \mathrm{Mark} H F$, editors. International Symposium on the History of Organic Coatings, held September 11-15, 1989, in Miami Beach, Florida, USA1. New York: Elseveir Science Publishing Co., Inc.; 1990. p. 1-7.

24. Mills JS, White R. The organic chemistry of museum objects. Reprint. Oxford: Butterworth-Heinemann; 1996. p. 134.

25. Morgan J. Conservation of plastics: an introduction. London: Plastics Historical Society; 1991. p. 28.

26. Quye A, Williamson C. editors. Plastics: collecting and conserving. Edinburgh: NMS Publishing Ltd; 1999. p. 72, 76

27. Gardner WH, Rheineck AE, Long JS, Gardner HA. The paint and varnish industry. In: Mattiello JJ, editor. Raw materials for varnishes and vehicles, vol. I. 3rd ed. New York: Wiley; 1946.

28. Damitz FM, Murphy JA, Mattiello JJ. Varnishes. In: Mattiello JJ, editor. Protective and Decorative Coatings, vol. III. 3rd ed. New York: Wiley; 1947. p. 202.

29. Ploeger R, Chiantore O. Characterization and stability issues of artists' alkyd paints. Smithson Contrib Museum Conserv. 2010;3:92. https:// repository.si.edu/bitstream/handle/10088/20494/16.Ploeger.SCMC3. Mecklenburg.Web.pdf? sequence=1. Accessed 28 Jan 2017.

30. How to recondition fabric bodywork. The coach and motor body builder for Australia and New Zealand. [Microform] National Library of Australia; 1930. p. 178.

31. Davies J. On painted ceilings: the techniques of Baroque murals in England. Conserv. 1996;20:15-27. 
32. Brunn M. Treatment of cellulose nitrate coated upholstery. In: Williams MA, editor. Upholstery conservation: preprints of a symposium held at colonial Williamsburg February 2-4, 1990. East Kingston: American Conservation Consortium, Ltd; 1990. p. 449-61.

33. Caple C. Objects: reluctant witnesses to the past. 2008th ed. Abingdon: Routledge; 2006.

34. Doyal S. The treatment of the Wellington Museum Apsley House Hall Porter's Chair: a case study of the treatment of coated fabric. Conserv. 1996;20:77-86.

35. White JL. Principles of polymer engineering rheology. New York: Wiley; 1990. p. 49. https://books.google.com.au/books?id=q9X5C_0kpglC\&q= macintosh\#v=snippet\&q=macintosh\&f=false. Accessed 29 Jan 2017.

36. Dexter DE. Production of coated fabrics: coating techniques Coated fabrics for membrane structures' Melbourne 30th \& 31st May, 1984. Sydney: Melbourne Structures Association of Australasia; 1984. p. 3.

37. Ash I, Ash M. Knovel (Firm). Handbook of fillers, extenders, and diluents, 2nd ed. Endicott: Synapse Information Resources; 2007. p. 285. https:// books.google.com.au/books?id $=C 4 C r 8 d H u p V s C \& p g=P A 285 \& d q=k a o l i n$ \&hl=en\&sa =X\&ved=0ahUKEwiR7IC30PDPAhVJ6GMKHeoeD7oQ6AEIQjA $H \# \vee=o n e p a g e \& q=k a o l i n \& f=f a l s e$. Accessed 23 October 2016.

38. Wei S, Pintus V, Schreiner M. A comparison study of alkyd resin used in art works by Py-GC/MS and GC/MS: The influence of aging. J Anal Appl Pyrolysis. 2013;104(November):441-7. p. 444, 446. http://www.sciencedirect. com/science/article/pii/S0165237013001307. Accessed 6 Feb 2017.
39. Agilent Technologies. What are the common contaminants in my GCMS. https://www.agilent.com/cs/library/Support/Documents/FAQ232F05001. pdf. Accessed 29 Sept 2016.

40. Eastman Chemical Company. Eastman ${ }^{\mathrm{TM}}$ TEG-EH Plasticizer. 2015. http://www.eastman.com/Products/Pages/ProductHome. aspx?Product=71001058. Accessed 13 Sept 2016.

41. Verleye GAL, Roeges NPG, De Moor MO. Easy identification of plastics and rubbers. Shropshire: Rapra Technology Limited; 2001. p. p47.

42. Sutherland K, del Rio JC. Characterisation and discrimination of various types of lac resin using gas chromatography mass spectrometry techniques with quaternary ammonium reagents. J Chromatogr. 2014;1338:149-63. http://www.sciencedirect.com/science/article/pii/ S0021967314003252. Accessed 28 Jan 2017

43. Ribechini E, Orsini S, Silvano F, Colombini MP. Py-GC/MS, GC/MS and FTIR Investigations on late Roman-Egyptian adhesives from Opus Sectile: new insights into ancient recipes and technologies. Analytica Chimica Acta. 2009; 638(1):79-87. http://www.sciencedirect.com/science/article/pii/ S0003267009002219. Accessed 30 September 2016.

44. Learner T. Modern paints uncovered: proceedings from the modern paints uncovered symposium. Los Angeles: Getty Publications; 2007. p. 15. https://books.google.com.au/books?id=ia9V2mls3K4C\&dq=cellulose +nitrate+Py-GC-MS+spectra\&source=gbs_navlinks_s. Accessed 20 Oct 2016.

\section{Submit your manuscript to a SpringerOpen ${ }^{\circ}$ journal and benefit from:}

- Convenient online submission

- Rigorous peer review

- Immediate publication on acceptance

- Open access: articles freely available online

- High visibility within the field

- Retaining the copyright to your article

Submit your next manuscript at $>$ springeropen.com 